\title{
Weak interactions between hypohalous acids and dimethylchalcogens $\dagger$
}

\author{
Goar Sánchez-Sanz, ${ }^{a}{ }^{a}$ Cristina Trujillo, ${ }^{a b}$ Ibon Alkorta $^{a}$ and José Elguero ${ }^{a}$ \\ Received 24th March 2012, Accepted 8th May 2012 \\ DOI: $10.1039 / \mathrm{c} 2 \mathrm{cp} 40949 \mathrm{f}$
}

The complexes formed between dimethylchalcogens $\mathrm{X}\left(\mathrm{CH}_{3}\right)_{2}(\mathrm{X}=\mathrm{S}$, Se, and Te $)$ and hypohalous acids $\mathrm{YOH}(\mathrm{Y}=\mathrm{F}, \mathrm{Cl}, \mathrm{Br}$, and I) have been studied at the MP2/aug'-cc-pVTZ computational level, five minima structures being located. Two of them correspond to hydrogen bonds (HB), another two to halogen bonds (XB) with the chalcogen acting as an electron donor, the last one showing a $\mathrm{C}-\mathrm{H} \cdots \mathrm{O}$ contact. The most stable complexes of $\mathrm{IOH}$ and $\mathrm{BrOH}$ acids present halogen $\cdots$ chalcogen interactions with interaction energies, $E_{\mathrm{i}}$, up to $-49 \mathrm{~kJ} \mathrm{~mol}^{-1}$. In the case of the $\mathrm{ClOH}$ and $\mathrm{FOH}$ molecules, the hydrogen bonded complexes are more stable with interaction energies between -27 and $-34 \mathrm{~kJ} \mathrm{~mol}^{-1}$. Linear correlations between the molecular electrostatic potential (MEP) stationary points at the van der Waals surface and the interaction energy have been found. The contribution of the different energy terms to the total interaction energy was analyzed by means of the DFT-SAPT theory finding that the electrostatic attractive term is dominant in the complexes with $\mathrm{HB}$ and $\mathrm{XB}$, excepting a few cases in which the dispersion and induction terms become more important than the electrostatic one.

\section{Introduction}

Dimethyl derivatives of sulfur, selenium and tellurium are amongst the smallest organo-chalcogen molecules. Dimethyl sulfide (DMS), originated primarily from dimethylsulfoniopropionate (DMSP), is the most abundant biological sulfur compound emitted to the atmosphere, ${ }^{1,2}$ with a biological impact not only on the atmosphere but also on different environments including oceans $^{3,4}$ and Arctic ices. ${ }^{5}$ Selenium is an essential element present in traces in the organism. Dimethyl selenide (DMSe) is a naturally occurring organoselenium compound detected in a variety of plants and microorganisms. ${ }^{6}$ Dimethyl telluride (DMTe), a precursor of mercury cadmium telluride, ${ }^{8}$ has been found to be a product of microbial metabolism produced by some fungi and bacteria. ${ }^{7}$

The structural parameters of the $\mathrm{X}\left(\mathrm{CH}_{3}\right)_{2}$ chalcogen derivatives $(\mathrm{X}=\mathrm{S}, \mathrm{Se}$, and $\mathrm{Te}$ ) have been determined by $\mathrm{MW}$ spectroscopy. The parameters obtained for these compounds have been compared to those of other related derivatives. ${ }^{9}$ Early ab initio studies of the $\mathrm{X}\left(\mathrm{CH}_{3}\right)_{2}$ molecules reported the conformational preference of the methyl groups, the performance of different bases to reproduce the experimental geometries and dipole moments and the first ionization potentials. ${ }^{10,11}$

\footnotetext{
a Instituto de Química Médica, CSIC, Juan de la Cierva 3, E-28006, Madrid,Spain.E-mail: goar@iqm.csic.es,

Web: http://www.iqm.csic.es/are

${ }^{b}$ Departamento de Ciencia e Ingeniería de Materiales e Ingeniería Quimica, Universidad Carlos III, Avda de la Universidad 30,

E-28911, Leganés, Madrid, Spain

$\dagger$ Electronic supplementary information (ESI) available. See DOI: $10.1039 / \mathrm{c} 2 \mathrm{cp} 40949 \mathrm{f}$
}

The hypohalous acids ( $\mathrm{HOX}$ with $\mathrm{X}=\mathrm{F}, \mathrm{Cl}, \mathrm{Br}$, or $\mathrm{I}$ ) are powerful oxidizing agents and can be easily formed in the atmosphere (e.g., through reactions between the $\mathrm{X}$ and $\mathrm{OH}$ radicals). They are of particular interest due to the interplay between the $\sigma$-inductive role ${ }^{12,13}$ of the halogen atom in HOX and the repulsive interactions between the lone pairs of the adjacent oxygen and halogen atoms. ${ }^{14} \mathrm{~A}$ number of studies have characterized the hydrogen bonded cluster formed by the hypohalous acids with themselves ${ }^{15}$ or with other molecules. ${ }^{16-25}$

In the present article, the complexes formed between the dimethylchalcogen derivatives and the hypohalous acids have been explored theoretically. Due to the characteristics of the molecules, a variety of interactions are expected as hydrogen bonds and halogen-chalcogen contacts. The importance of both interactions, and in particular, the role that the $\sigma$-hole plays in the halogen bonding, has been highlighted and widely studied in several publications. ${ }^{26-28}$ The electron density of the complexes has been analyzed with the Atoms in Molecules (AIM) methodology and the interaction between the occupied and empty orbitals has been explored with the Natural Bond Orbital (NBO) method. In addition, the different components of the interaction energy have been evaluated with the DFT-SAPT methodology.

\section{Computational details}

All the geometries of the complexes formed between the $\mathrm{X}\left(\mathrm{CH}_{3}\right)_{2}$ and the $\mathrm{YOH}$ acids were fully optimized at second order Møller-Plesset perturbation theory (MP2) level with the aug'-cc-pVTZ basis set, ${ }^{29}$ which is the Dunning aug-cc-pVTZ 
basis set ${ }^{30,31}$ without diffuse functions on $\mathrm{H}$ atoms. For heavy atoms, $\mathrm{Te}^{32}$ and $\mathrm{I},{ }^{33}$ the aug-cc-pVTZ-PP pseudopotential basis set was used. Harmonic vibrational frequencies were computed at the same level used in order to verify that the structures obtained correspond to local minima. The interaction energies, $E_{\mathrm{i}}$, have been calculated as the difference of the total energy of the complex and the sum of the isolated monomers. They have been corrected for the inherent basis set superposition error (BSSE) using the Boys-Bernardi ${ }^{34,35}$ counterpoise technique. All the calculations have been carried out with the Gaussian09 program. $^{36}$

The molecular electrostatic potential (MEP) of the isolated monomers has been calculated on the electron density isosurface of 0.001 a.u. This isosurface has been shown to resemble the van der Waals surface. ${ }^{37}$ These calculations have been carried out with the facilities of the Gaussian-09 program and the numerical results depicted using the WFA program. ${ }^{38}$ Regions with negative MEP values are susceptible to interact with electron deficient moieties, such as HB donors, while positive regions can interact with electron rich areas.

The bonding characteristics were analyzed by means of the atoms in molecules (AIM) theory. ${ }^{39,40}$ For this purpose we have located the most relevant bond critical points (BCPs), and evaluated the electron density at each of them, with the facilities of AIMALL programs. ${ }^{41}$ All the interactions were characterized by the formation of a BCP between the atoms involved that are connected by the corresponding bond paths.

The Natural Bond Orbital (NBO) method ${ }^{42}$ has been employed to evaluate atomic charges using the NBO-3 program, included within the Gaussian-09 program, and to analyze charge-transfer interactions between occupied and empty orbitals.

The different terms of the interaction energy were calculated with the SAPT methodology. ${ }^{43}$ The DFT-SAPT calculations

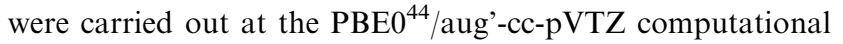
level, except for Te and I, where the aug-cc-pVTZ-PP pseudopotential basis set was used. When using the PBE0 functional, the asymptotic correction was included using the experimental ionization potentials of the $\mathrm{X}\left(\mathrm{CH}_{3}\right)$ molecules, ${ }^{45} \mathrm{FOH},{ }^{46}$

Table 1 Structural data for $\mathrm{X}\left(\mathrm{CH}_{3}\right)_{2}$ monomers $(\mathrm{X}=\mathrm{S}$, Se, and Te) at the MP2/aug'-cc-pVTZ/aug-cc-pVTZ-PP computational level. Experimental data are in parentheses. Bond distances in $\AA$ and angles in

\begin{tabular}{lll}
\hline $\mathrm{X}\left(\mathrm{CH}_{3}\right)_{2}$ & $\mathrm{X}-\mathrm{C}$ bond distance $(\AA)$ & $\mathrm{C}-\mathrm{X}-\mathrm{C}$ angle $\left(^{\circ}\right)$ \\
\hline $\mathrm{S}$ & $1.804(1.802)^{45,51}$ & $98.0(98.9)^{45,51}$ \\
$\mathrm{Se}$ & $1.935(1.943)^{45}$ & $95.6(96.2)^{45}$ \\
$\mathrm{Te}$ & $2.130(2.141)^{45}$ & $93.4(93.5)^{45}$ \\
\hline
\end{tabular}

$\mathrm{ClOH},{ }^{47} \mathrm{BrOH}^{48}$ and $\mathrm{IOH}^{49}$ All of these calculations have been performed using the MOLPRO program. ${ }^{50}$

\section{Results and discussion}

\section{Monomers}

Dimethyl chalcogenides. The geometric structural parameters of the isolated dimethyl chalcogen derivatives have been gathered in Table 1. The bond distance between the chalcogen and carbon atoms and the $\mathrm{C}-\mathrm{X}-\mathrm{C}$ angles are in good agreement with those found in the experimental reports in gas phase.

Fig. 1 illustrates the calculated MEP of the $\mathrm{X}\left(\mathrm{CH}_{3}\right)_{2}$ monomers plotted on the 0.001 a.u. electron density isosurface. Positive values of the electrostatic potential are represented in red while the most negative regions are in blue color. The two negative zones located close to the chalcogen atoms at both sides of the molecular plane can be observed (only one is shown in Fig. 1). These can be associated with the lone pairs belonging to the chalcogen atom.

Table 2 reports the values of the absolute MEP minima and the MEP minima on the vdW surface. The magnitudes of the absolute MEP minima decrease in the order $\mathrm{S}>\mathrm{Se}>\mathrm{Te}$. Likewise, the MEP on the vdW surface follows the same trend as the absolute MEP minima. This effect can also be observed in Fig. 1, where the blue area associated with the chalcogen lone pairs contracts with the chalcogen size. The maxima values of the MEP on the vdW surface corresponding to the $\mathrm{H}$ atoms are also summarized in Table 2. Those positive values make the region around the $\mathrm{H}$ atoms susceptible to a nucleophilic attack by the hypohalous acids.

Hypohalous acids. The electronic and structural properties of hypohalous acids were already theoretically calculated and discussed in a previous work. ${ }^{24}$ For the sake of completeness, the energy minima structures have been re-optimized at the same computational level used in the present article. The geometrical parameters obtained, Table 3, bond distances, both $\mathrm{O}-\mathrm{Y}$ and $\mathrm{H}-\mathrm{O}$, as well as the $\mathrm{H}-\mathrm{O}-\mathrm{Y}$ angles, resemble closely those found experimentally.

Table 2 Molecular electrostatic potential absolute minima for $\mathrm{X}\left(\mathrm{CH}_{3}\right)_{2}$ monomers $(\mathrm{X}=\mathrm{S}, \mathrm{Se}$, and $\mathrm{Te})$, the minimum value on the van der Waals surface of the $\mathrm{X}$ atoms and maxima of $\mathrm{H}$ atoms in a.u. at the MP2/aug'-cc-pVTZ/aug-cc-pVTZ-PP computational level

\begin{tabular}{llll}
\hline $\mathrm{X}\left(\mathrm{CH}_{3}\right)_{2}$ & $\mathrm{~S}$ & $\mathrm{Se}$ & \multicolumn{1}{c}{$\mathrm{Te}$} \\
\hline Min & -0.050 & -0.048 & -0.038 \\
vdW & -0.036 & -0.034 & -0.031 \\
H atoms & 0.024 & 0.025 & 0.024 \\
\hline
\end{tabular}
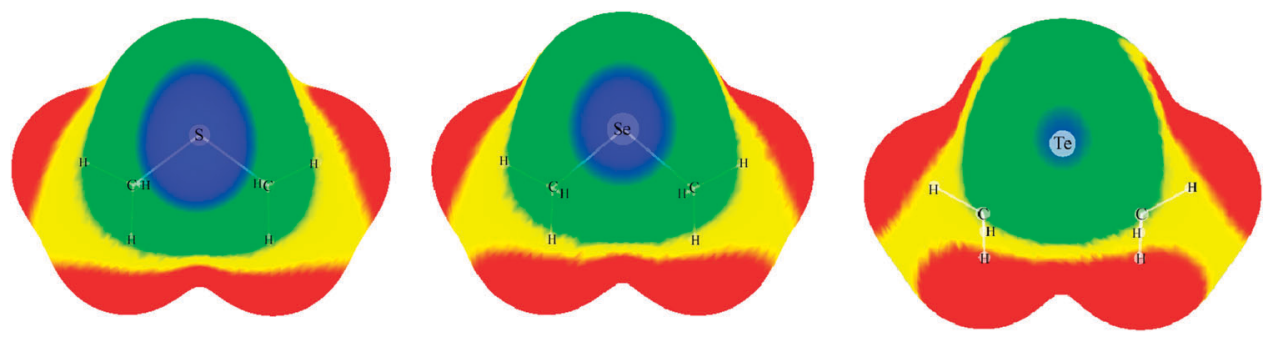

Fig. 1 Molecular electrostatic potential for the $\mathrm{X}\left(\mathrm{CH}_{3}\right)_{2}(\mathrm{X}=\mathrm{S}$, Se, and Te from left to right), on the 0.001 a.u. isodensity surface. Color values of the MEP: red $>0.01$, yellow $>0.00$, green $>-0.03$, blue $<-0.03$ a.u. 
Table 3 Structural data for $\mathrm{YOH}$ monomers $(\mathrm{Y}=\mathrm{F}, \mathrm{Cl}, \mathrm{Br}$, and I) at the MP2/aug'-cc-pVTZ/aug-cc-pVTZ-PP computational level. Experimental data in parentheses. Bond distances in $\AA$ and angles in

\begin{tabular}{llll}
\hline YOH & $\begin{array}{l}\text { O-Y bond distance } \\
(\AA)\end{array}$ & $\begin{array}{l}\mathrm{H}-\mathrm{O} \text { bond distance } \\
(\AA)\end{array}$ & $\begin{array}{l}\mathrm{H}-\mathrm{O}-\mathrm{Y} \text { angle } \\
\left({ }^{\circ}\right)\end{array}$ \\
\hline $\mathrm{F}$ & $1.429(1.442)^{52}$ & $0.970(0.964)^{52}$ & $97.9(97.2)^{52}$ \\
$\mathrm{Cl}$ & $1.697(1.689)^{53}$ & $0.969(0.964)^{53}$ & $102.5(102.9)^{53}$ \\
$\mathrm{Br}$ & $1.815(1.828)^{54}$ & $0.967(0.964)^{54}$ & $103.3(103.1)^{54}$ \\
$\mathrm{I}$ & $1.992(1.994)^{55}$ & $0.969(0.967)^{55}$ & $104.3(103.9)^{55}$ \\
\hline
\end{tabular}

Table 4 Molecular electrostatic potential absolute minima for $\mathrm{YOH}$ monomers ( $\mathrm{Y}=\mathrm{F}, \mathrm{Cl}, \mathrm{Br}$, and $\mathrm{I})$, MEP maxima associated with the $\sigma$-hole of the halogens and the value on the 0.001 a.u. isodensity surface at the MP2/aug'-cc-pVTZ/aug-cc-pVTZ-PP computational level

\begin{tabular}{lllll}
\hline YOH & F & $\mathrm{Cl}$ & $\mathrm{Br}$ & \multicolumn{1}{l}{$\mathrm{I}$} \\
\hline Y-Min & -0.0272 & -0.0150 & -0.0125 & -0.0099 \\
Y-vdW & -0.0249 & -0.0149 & -0.0125 & -0.0096 \\
O-Min & -0.0352 & -0.0394 & -0.0422 & -0.0466 \\
O-vdW & -0.0275 & -0.0302 & -0.0321 & -0.0352 \\
H-vdW & 0.0970 & 0.0909 & 0.0876 & 0.0829 \\
- -Hole & -0.0009 & 0.0382 & 0.0504 & 0.0635 \\
\hline
\end{tabular}

The absolute MEP minima and the MEP minima on the vdW surface for $\mathrm{YOH}(\mathrm{Y}=\mathrm{F}, \mathrm{Cl}, \mathrm{Br}$, and $\mathrm{I})$ have been calculated and tabulated in Table 4. Two MEP minima have been found for each molecule, one of them associated with the oxygen lone pair and another with the halogen atom, the former being much deeper than the latter in all the monomers. The absolute MEP minima and MEP minima on the vdW surface associated with the halogen atoms vary in the same way, decreasing in absolute value with the size of the atom, whereas the opposite is true for the oxygen MEP values.

Positive values of the MEP on the vdW (Fig. 2) are found around the hydrogen and halogen atoms. The positive values around the hydrogen atom decrease as the size of the halogen atoms increases. These values are indicative of the HB donor capability of the corresponding molecule. The positive MEP values of the halogen atoms are located along the $\mathrm{X}-\mathrm{O}$ bond axis and they have been named $\sigma$-hole in the literature. ${ }^{56}$ These values vary from -0.0009 to 0.0635 , from the F to the I atom, respectively.

Binary complexes. The structures calculated for the $\mathrm{X}\left(\mathrm{CH}_{3}\right)_{2}$ : $\mathrm{YOH}$ dimers correspond to five different configurations, see Fig. 3. The first two configurations, I and II, correspond to those complexes in which the hypohalous acid acts as a HB donor, whether only a single hydrogen bond, HB,
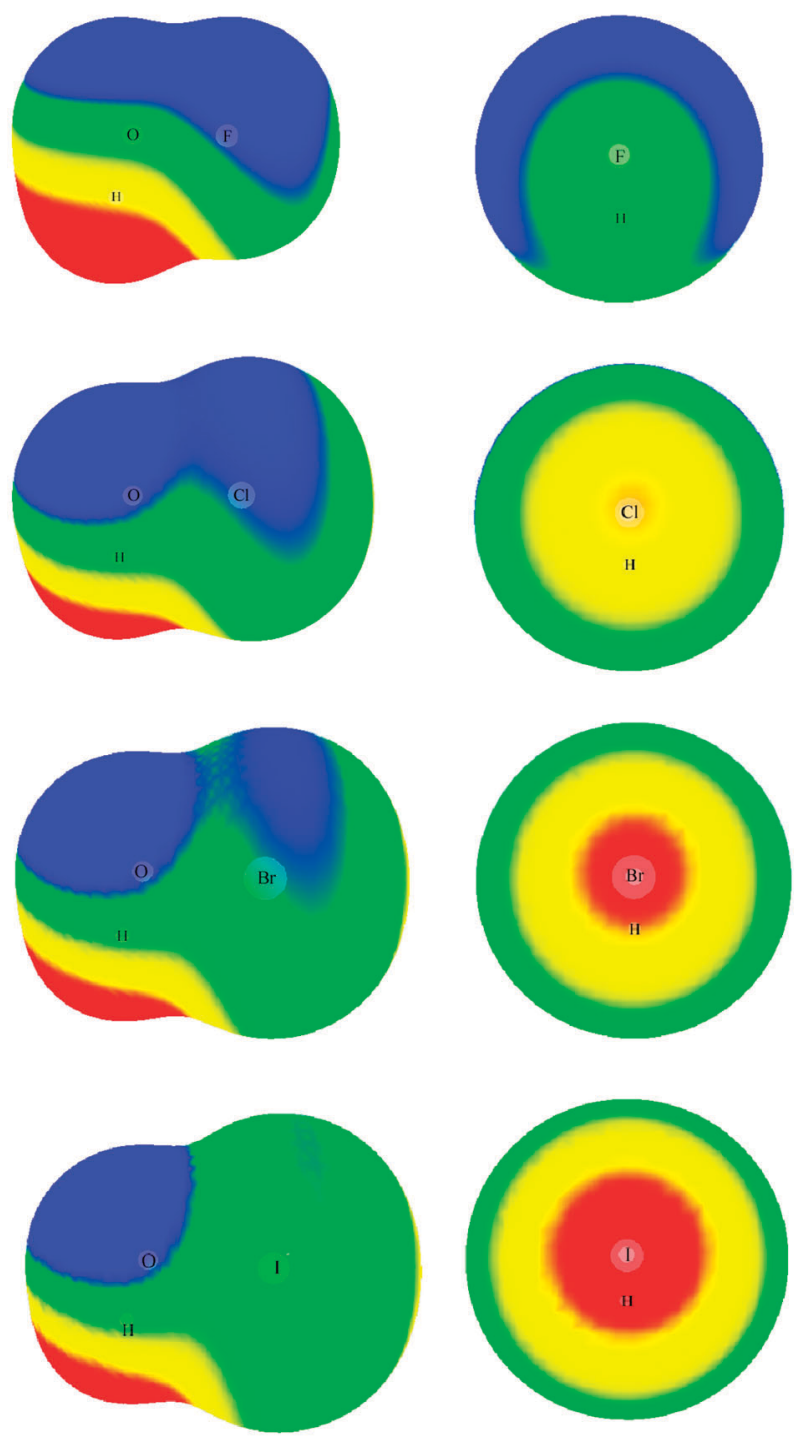

Fig. 2 Molecular electrostatic potential for the $\mathrm{YOH}(\mathrm{Y}=\mathrm{F}, \mathrm{Cl}, \mathrm{Br}$, and I, from up to down), on the 0.001 a.u. electron density isosurface. Color values of the MEP: red $>0.04$, yellow $>0.01$, green $>-0.01$, blue $<-0.01$ a.u. Left corresponds to side views. Right, $\sigma$-hole on the $\mathrm{Y}$ atom along the $\mathrm{Y}-\mathrm{O}$ bond axis.

is present (conf. I) or additional halogen-hydrogen interactions (conf. II) are exhibited. The third configuration corresponds to the complexes that exhibit $\mathrm{C}-\mathrm{H}$. . O interactions. In this case, the oxygen lone pairs interact with the regions where

Table 5 Interaction energies (in $\mathrm{kJ} \mathrm{mol}^{-1}$ ) BSSE corrected, variation of $\mathrm{O}-\mathrm{H}$ distance in $\mathrm{YOH}$ acids upon complexation, and $\mathrm{X} \cdots \mathrm{H}$ distance in the $\mathrm{HB}$ (in $\AA$ ) for the $\mathrm{X}\left(\mathrm{CH}_{3}\right)_{2}$ :YOH complexes in configurations I and II at the MP2/aug'-cc-pVTZ/aug-cc-pVTZ-PP computational level

\begin{tabular}{|c|c|c|c|c|c|c|c|c|c|c|}
\hline \multirow{2}{*}{$\frac{\mathrm{YOH}}{\mathrm{Y}}$} & \multirow[b]{2}{*}{ Conf. } & \multicolumn{3}{|l|}{$\mathrm{S}$} & \multicolumn{3}{|l|}{$\mathrm{Se}$} & \multicolumn{3}{|l|}{$\mathrm{Te}$} \\
\hline & & $E_{\mathrm{i}}$ & $\Delta d(\mathrm{O}-\mathrm{H})$ & $d(\mathrm{X} \cdots \mathrm{H})$ & $E_{\mathrm{i}}$ & $\Delta d(\mathrm{O}-\mathrm{H})$ & $d(\mathrm{X} \cdots \mathrm{H})$ & $E_{\mathrm{i}}$ & $\Delta d(\mathrm{O}-\mathrm{H})$ & $d(\mathrm{X} \cdots \mathrm{H})$ \\
\hline $\mathrm{F}$ & I & - & - & - & - & - & - & - & - & - \\
\hline $\mathrm{Cl}$ & I & -33.0 & 0.020 & 2.170 & -31.6 & 0.021 & 2.266 & -29.1 & 0.017 & 2.476 \\
\hline $\mathrm{Br}$ & I & -32.4 & 0.022 & 2.129 & -30.2 & 0.023 & 2.196 & -28.7 & 0.019 & 2.470 \\
\hline I & I & -31.8 & 0.019 & 2.173 & -30.7 & 0.020 & 2.265 & -27.2 & 0.018 & 2.498 \\
\hline $\mathrm{F}$ & II & -32.5 & 0.019 & 2.206 & -36.4 & 0.019 & 2.308 & -27.5 & 0.015 & 2.524 \\
\hline $\mathrm{Cl}$ & II & -34.4 & 0.020 & 2.199 & -33.5 & 0.020 & 2.297 & -30.7 & 0.017 & 2.506 \\
\hline $\mathrm{Br}$ & II & -33.5 & 0.022 & 2.175 & -31.8 & 0.022 & 2.253 & -30.6 & 0.018 & 2.504 \\
\hline I & II & -32.2 & 0.017 & 2.225 & -31.4 & 0.018 & 2.318 & -28.8 & 0.017 & 2.540 \\
\hline
\end{tabular}


molecular electrostatic is positive in the isolated $\mathrm{X}\left(\mathrm{CH}_{3}\right)_{2}$ monomers, which are associated with the hydrogens of the methyl groups. The complexes in configurations $\mathbf{I V}$ and $\mathbf{V}$ are those in which the hypohalous acids can act as a halogen bond (XB) donor, showing a single chalcogen $\cdots$ halogen interaction. The only difference between configurations IV and $\mathbf{V}$ is the orientation of the $\mathrm{OH}$ bond. Configuration IV is found to be a minimum in all the combinations of the dimethyl chalcogen derivatives and hypohalous acids considered here, while minima complexes in configuration $\mathbf{V}$ are only found for the hypoiodous acid complexes.

Configurations I and II: HB interactions. The complexes in which the hypohalous acids act as a HB donor correspond to the configurations I and II. The interaction energies, the variation of the $\mathrm{O}-\mathrm{H}$ distance with respect to the isolated hypohalous acids, and the $\mathrm{X} \cdot \mathrm{H}$ distance for these complexes have been summarized in Table 5 .

Complexes in configuration I do not present minima structures with hypofluorous acid and the optimization of these complexes always reverts to configuration II. In configuration I, the interaction energy ranges from -27.2 to $-33.0 \mathrm{~kJ} \mathrm{~mol}^{-1}$ and slightly decreases in absolute value with the size of the halogen of the acid involved.

In configuration II, the complexes with all the hypohalous acids are stable. The variation of the energy follows similar patterns as those found in the complexes in configuration $\mathbf{I}$, ranging from -27.5 to $-36.4 \mathrm{~kJ} \mathrm{~mol}^{-1}$. The complexes in configuration II present slightly deeper values of the interaction energy than in configuration $\mathbf{I}$ due to extra contacts between the halogen atoms and the hydrogen of the methyl groups. The electron density analysis of the complexes in configuration II shows the presence of an intermolecular $\mathrm{X} \cdots \mathrm{H}$ BCP and two BCPs associated with the interaction of the halogen atom with the hydrogen atoms of the methyl groups of the $\mathrm{X}\left(\mathrm{CH}_{3}\right)_{2}$ molecules. Based on the energy differences

Table $6 \mathrm{NBO}$ analysis for the $\mathrm{HB}$ for $\mathrm{X}\left(\mathrm{CH}_{3}\right)_{2}: \mathrm{YOH}$ complexes in configurations I and II at the MP2/aug'-cc-pVTZ/aug-cc-pVTZ-PP computational level. Orbital stabilization energy ( $\left.\mathrm{LP} X \rightarrow \sigma^{*} \mathrm{OH}\right)$ in $\mathrm{kJ} \mathrm{mol}^{-1}$, charge transfer in a.u.

\begin{tabular}{|c|c|c|c|c|c|c|c|}
\hline $\mathrm{YOH}$ & & S & & $\mathrm{Se}$ & & $\mathrm{Te}$ & \\
\hline Y & Conf. & $\begin{array}{l}\mathrm{LPX} \rightarrow \\
\sigma^{*} \mathrm{OH}\end{array}$ & $\begin{array}{l}\text { Charge } \\
\text { transfer }\end{array}$ & $\begin{array}{l}\mathrm{LPX} \rightarrow \\
\sigma^{*} \mathrm{OH}\end{array}$ & $\begin{array}{l}\text { Charge } \\
\text { transfer }\end{array}$ & $\begin{array}{l}\mathrm{LPX} \rightarrow \\
\sigma^{*} \mathrm{OH}\end{array}$ & $\begin{array}{l}\text { Charge } \\
\text { transfer }\end{array}$ \\
\hline F & I & - & - & - & - & - & - \\
\hline $\mathrm{Cl}$ & I & 19.5 & 0.069 & 21.0 & 0.079 & 18.8 & 0.081 \\
\hline $\mathrm{Br}$ & I & 20.3 & 0.074 & 24.9 & 0.089 & 18.6 & 0.081 \\
\hline I & I & 17.8 & 0.067 & 19.1 & 0.078 & 16.4 & 0.080 \\
\hline $\mathrm{F}$ & II & 18.2 & 0.063 & 19.2 & 0.071 & 16.6 & 0.070 \\
\hline $\mathrm{Cl}$ & II & 19.2 & 0.067 & 20.8 & 0.077 & 19.3 & 0.083 \\
\hline $\mathrm{Br}$ & II & 20.8 & 0.069 & 23.8 & 0.085 & 18.5 & 0.084 \\
\hline I & II & 16.5 & 0.059 & 18.2 & 0.073 & 15.9 & 0.081 \\
\hline
\end{tabular}

between the complexes in configurations I and II, it can be estimated that the $\mathrm{Y} \cdots \mathrm{H}$ interactions stabilized the latter complexes between $1-2 \mathrm{~kJ} \mathrm{~mol}^{-1}$.

Among all the complexes in both configurations I and II, the one that shows the most stable interaction energy in absolute value corresponds to that formed by the sulfur derivative with the hypochlorous acid in configuration II. This may be because chlorine presents a compromise electronegativity value to make $\mathrm{HOCl}$ a good $\mathrm{HB}$ donor and, at the same time, the lone pairs of the $\mathrm{Cl}$ atom present an optimal spatial disposition (see Fig. 2). In addition, the values of the MEP of the $\mathrm{S}\left(\mathrm{CH}_{3}\right)_{2}$ (see Table 4) favor the interaction between its lone pairs and the hydrogen atoms. The complex $\mathrm{Te}\left(\mathrm{CH}_{3}\right)_{2}$ :HOI in configuration I presents the smallest value of the interaction energy due to both the smallest value of the electronegativity of the I atom which makes the IOH the poorer HB donor of those considered here, combined with electronegativity of the $\mathrm{Te}$ which makes $\mathrm{Te}\left(\mathrm{CH}_{3}\right)_{2}$ a poor electron donor.

Regarding the structural parameters, the $\mathrm{X} \cdot \mathrm{H}$ distance in both configurations decreases with the size of the halogen atom, except for the iodine derivative. In addition, all the complexes show an elongation in the $\mathrm{H}-\mathrm{O}$ bond of the hypohalous acids between 0.015 and $0.023 \AA$ with respect to the isolated monomer.

The NBO results reported in Table 6 show the stabilization energy values of the orbital interaction due to the charge transfer from the lone pair of the chalcogen atom to the antibonding $\mathrm{O}-\mathrm{H}$. The charge transfers are larger than those values found for some hydrogen bonds studied in the literature (i.e. $\mathrm{H}_{3} \mathrm{~N} \cdots \mathrm{HOH}=0.0269$ a.u., $\mathrm{HF} \cdots \mathrm{HF}=0.0124$ a.u.). ${ }^{57}$ The iodine $E(2)$ values ( $\mathrm{LP} \mathrm{X} \rightarrow \sigma^{*} \mathrm{OH}$ ) are the smallest in each series.

Configuration III: C-H. . O interactions. Configuration III corresponds to those complexes that exhibit $\mathrm{C}-\mathrm{H} \cdots \mathrm{O}$ interactions, in which the oxygen atom of the hypohalous acid presents two simultaneous contacts with two hydrogen atoms of the methyl groups. The complexes in configuration III with hypofluorous and hypoiodous acids are not stable and they both revert to configuration II minimum structure. This behavior may be explained by two reasons: (a) in the case of $\mathrm{FOH}$, the high value of electronegativity makes the $\mathrm{F}$ atom withdraw electron density from the $\mathrm{O}$ atom and, thus, the interaction through the lone pairs of the $\mathrm{O}$ atom becomes inefficient, (b) in the case of $\mathrm{IOH}$, the steric repulsions between the electron clouds of the I atom and of the methyl group are very large and, therefore, prevent the formation of the complexes.

As it can be observed in Table 7, the values of the interaction energies present a narrow range, between 8.2 and $9.1 \mathrm{~kJ} \mathrm{~mol}^{-1}$. These values are three to four times weaker than those found in configurations I and II.

Table 7 Interaction energies (in $\mathrm{kJ} \mathrm{mol}^{-1}$ ) BSSE corrected, variation of $\mathrm{C}-\mathrm{H}$ distance in methylenes of $\mathrm{X}\left(\mathrm{CH}_{3}\right)_{2}$, and $\mathrm{H} \cdots \mathrm{O}$ distance (in $\AA$ ) for the $\mathrm{X}\left(\mathrm{CH}_{3}\right)_{2}$ :YOH complexes in configuration III at the MP2/aug'-cc-pVTZ/aug-cc-pVTZ-PP computational level

\begin{tabular}{|c|c|c|c|c|c|c|c|c|c|c|}
\hline \multirow{2}{*}{$\frac{\mathrm{YOH}}{\mathrm{Y}}$} & \multirow[b]{2}{*}{ Conf. } & \multicolumn{3}{|l|}{$\underline{S}$} & \multicolumn{3}{|l|}{$\underline{\mathrm{Se}}$} & \multicolumn{3}{|l|}{$\underline{\mathrm{Te}}$} \\
\hline & & $E_{\mathrm{i}}$ & $\Delta d(\mathrm{C}-\mathrm{H})$ & $d(\mathrm{H} \cdots \mathrm{O})$ & $E_{\mathrm{i}}$ & $\Delta d(\mathrm{C}-\mathrm{H})$ & $d(\mathrm{H} \cdots \mathrm{O})$ & $E_{\mathrm{i}}$ & $\Delta d(\mathrm{C}-\mathrm{H})$ & $d(\mathrm{H} \cdots \mathrm{O})$ \\
\hline$\overline{\mathrm{Cl}}$ & III & -8.2 & -0.0005 & 2.598 & -8.6 & -0.001 & 2.547 & -8.8 & -0.001 & 2.490 \\
\hline $\mathrm{Br}$ & III & -8.2 & -0.001 & 2.510 & -8.4 & -0.001 & 2.439 & -9.1 & -0.001 & 2.448 \\
\hline
\end{tabular}



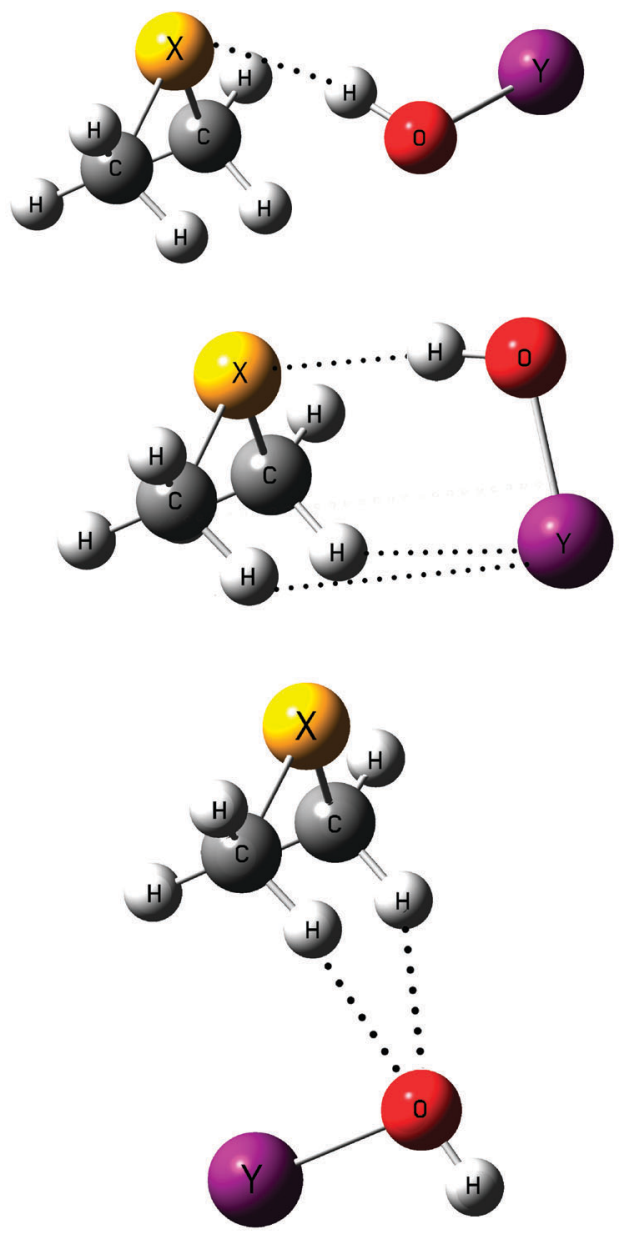

III

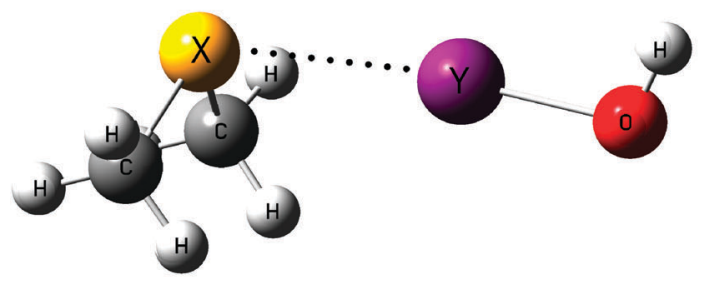

IV

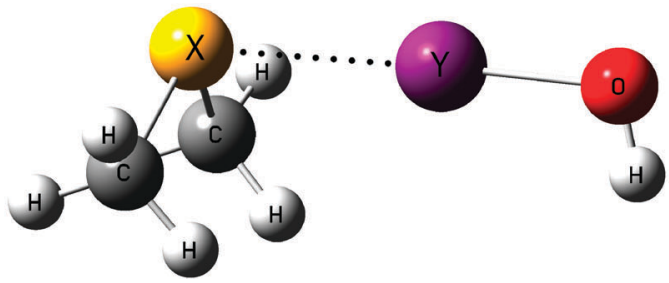

Fig. 3 Some representative minimum-energy structures of the five different complexes between $\mathrm{X}\left(\mathrm{CH}_{3}\right)_{2}$ and $\mathrm{YOH}$ at the MP2/aug'-ccpVTZ/aug-cc-pVTZ-PP computational level.

The $\mathrm{H} \cdots \mathrm{O}$ interaction distances, reported in Table 7, decrease as the size of both chalcogen and halogen atoms increases. These results are in agreement with the analysis of the MEP of the isolated molecules that shows more negative values of the MEP minima associated with the oxygen atom with the increasing size of the halogen atom in the hypohalous acids and more positive values associated with the methyl groups in the $\mathrm{X}\left(\mathrm{CH}_{3}\right)_{2}$ molecules as the chalcogen atom is larger. The complex formation results in a very small shortening of the $\mathrm{C}-\mathrm{H}$ distances with respect to the isolated monomers.

The NBO results support the weakness of the $\mathrm{C}-\mathrm{H} \cdots \mathrm{O}$ interaction, revealing that the stabilization energy corresponding to the transfer from the lone pair of the $\mathrm{O}$ atom to the $\sigma^{*} \mathrm{C}-\mathrm{H}$ of the methyl groups is less than $4 \mathrm{~kJ} \mathrm{~mol}^{-1}$.

Configurations IV and V: halogen bonds. The last two minima conformations found are those where a single halogen bond (XB) interaction occurs, involving solely the chalcogen and halogen atoms of their respective monomers. The only difference between configurations $\mathbf{I V}$ and $\mathbf{V}$ is the spatial disposition of the hydrogen of $\mathrm{YOH}$ which can be towards the $\mathrm{CH}_{3}$ groups of the chalcogen derivative $(\mathbf{V})$ or in the opposite direction (IV) (see Fig. 3). Configuration IV is a minimum for all the combinations of $\mathrm{X}\left(\mathrm{CH}_{3}\right)_{2}$ and $\mathrm{YOH}$ molecules considered here. Configuration $\mathbf{V}$ is only a minimum for the complexes with $\mathrm{IOH}$, reverting in the rest of the cases spontaneously to the complexes in configuration IV.

The interaction energy (Table 8) ranges from -5.8 to $-49.1 \mathrm{~kJ} \mathrm{~mol}^{-1}$ and is highly dependent on the halogen involved within the contact. The interacting energy increases, in absolute values, with the size of the halogen involved due to the enlargement of the $\sigma$-hole and its polarizability. In addition, the evolution of the interaction energy along the chalcogen series remains almost constant with the variation of the chalcogen atom, except in the case of $\mathrm{IOH}$ complexes where an increment of $4.2 \mathrm{~kJ} \mathrm{~mol}^{-1}$ from $\mathrm{S}$ to Te is observed. The FOH complexes in configuration IV are much weaker than the rest, showing interaction energies between 5.8 and $5.9 \mathrm{~kJ} \mathrm{~mol}^{-1}$. These results can be explained based on the values of the MEP associated with the fluorine atoms which are slightly negative, disfavoring the interaction with the lone pair of the chalcogen atoms.

The variation of the $\mathrm{O}-\mathrm{Y}$ distance, $\Delta d(\mathrm{O}-\mathrm{Y})$, in the hypohalous acids with respect to the isolated monomers and the $\mathrm{X} \cdots \mathrm{Y}$ interaction distances are gathered in Table 8 . The values of $\Delta d(\mathrm{O}-\mathrm{Y})$ increase with the size of the halogen atom, following the same trend found for the interaction energy values, except in the case of $\mathrm{IOH}$. Moreover, the increase of the $\Delta d(\mathrm{O}-\mathrm{Y})$ with the size of the $\mathrm{X}$ atom is observed for the chalcogen series, as well.

The AIM results show the presence of BCP between the halogen atom $(\mathrm{Y})$ and the chalcogen atom $(\mathrm{X})$ with $\rho$ values which vary between 0.036 and 0.050 a.u. similar to those found for $\mathrm{XB}$ as the $\mathrm{NH}_{3} \cdots \mathrm{YOH}^{20}$ and $\mathrm{NH}_{3} \cdots \mathrm{XY}(\mathrm{X}, \mathrm{Y}=\mathrm{F}, \mathrm{Cl}, \mathrm{Br})$ complexes previously reported in the literature. ${ }^{58}$

In the case of $\mathrm{X}\left(\mathrm{CH}_{3}\right)_{2}: \mathrm{FOH}$ complexes, AIM analyses show the presence of BCP between the chalcogen atom and the $\mathrm{F}$ atom, with electron densities of $0.004-0.008$, which are smaller than those found in the XB of the rest of the complexes in configuration IV. Moreover, these complexes with $\mathrm{FOH}$ show two additional BCPs corresponding to the interaction between the $\mathrm{F}$ atom and the $\mathrm{H}$ atom of the methylenes, with small values of $\rho$ (see ESI $\dagger$ ). 
Table 8 Interaction energies (in $\mathrm{kJ} \mathrm{mol}^{-1}$ ) BSSE corrected, variation of $\mathrm{O}-\mathrm{Y}$ distance in $\mathrm{YOH}$ acids upon complexation, and $\mathrm{X} \cdots \mathrm{Y}$ distance (in $\AA$ ) in the chalcogen $\cdots$ halogen contact for $\mathrm{X}\left(\mathrm{CH}_{3}\right)_{2}$ :YOH complexes in configurations IV and $\mathbf{V}$ at the MP2/aug'-cc-pVTZ/aug-cc-pVTZ-PP computational level

\begin{tabular}{|c|c|c|c|c|c|c|c|c|c|c|}
\hline \multirow{2}{*}{$\frac{\mathrm{YOH}}{\mathrm{Y}}$} & \multirow[b]{2}{*}{ Conf. } & \multicolumn{3}{|l|}{$\underline{S}$} & \multicolumn{3}{|l|}{$\mathrm{Se}$} & \multicolumn{3}{|l|}{$\mathrm{Te}$} \\
\hline & & $E_{\mathrm{i}}$ & $\Delta d(\mathrm{O}-\mathrm{Y})$ & $d(\mathrm{X} \cdots \mathrm{Y})$ & $E_{\mathrm{i}}$ & $\Delta d(\mathrm{O}-\mathrm{Y})$ & $d(\mathrm{X} \cdots \mathrm{Y})$ & $E_{\mathrm{i}}$ & $\Delta d(\mathrm{O}-\mathrm{Y})$ & $d(\mathrm{X} \cdots \mathrm{Y})$ \\
\hline $\mathrm{F}$ & IV & -5.9 & 0.004 & 3.212 & -5.9 & 0.005 & 3.235 & -5.8 & 0.001 & 3.558 \\
\hline $\mathrm{Cl}$ & IV & -23.5 & 0.038 & 2.798 & -23.9 & 0.054 & 2.819 & -23.8 & 0.095 & 2.829 \\
\hline $\mathrm{Br}$ & IV & -34.9 & 0.062 & 2.684 & -35.4 & 0.080 & 2.726 & -39.1 & 0.109 & 2.850 \\
\hline I & IV & -45.1 & 0.046 & 2.854 & -47.2 & 0.055 & 2.928 & -49.1 & 0.071 & 3.060 \\
\hline I & $\mathbf{V}$ & -44.2 & 0.046 & 2.854 & -46.4 & 0.055 & 2.927 & -48.4 & 0.071 & 3.059 \\
\hline
\end{tabular}

Table $9 \mathrm{NBO}$ analysis for the $\mathrm{XB}$ for $\mathrm{X}\left(\mathrm{CH}_{3}\right)_{2}: \mathrm{YOH}$ complexes IV and $\mathbf{V}$ at the MP2/aug'-cc-pVTZ computational level

\begin{tabular}{|c|c|c|c|c|c|c|c|}
\hline \multicolumn{2}{|l|}{$\mathrm{YOH}$} & \multicolumn{2}{|l|}{$\mathrm{S}$} & \multicolumn{2}{|l|}{$\mathrm{Se}$} & \multicolumn{2}{|l|}{$\mathrm{Te}$} \\
\hline Y & & $\begin{array}{l}\mathrm{LPX} \rightarrow \\
\sigma^{*} \mathrm{OY}\end{array}$ & $\begin{array}{l}\text { Charge } \\
\text { transfer }\end{array}$ & $\begin{array}{l}\mathrm{LPX} \rightarrow \\
\sigma^{*} \mathrm{OY}\end{array}$ & $\begin{array}{l}\text { Charge } \\
\text { transfer }\end{array}$ & $\begin{array}{l}\mathrm{LPX} \rightarrow \\
\sigma^{*} \mathrm{OY}\end{array}$ & $\begin{array}{l}\text { Charge } \\
\text { transfer }\end{array}$ \\
\hline $\mathrm{F}$ & IV & 0.8 & 0.008 & 1.2 & 0.015 & 1.5 & 0.022 \\
\hline $\mathrm{Cl}$ & IV & 17.5 & 0.138 & 22.0 & 0.187 & 36.3 & 0.288 \\
\hline $\mathrm{Br}$ & IV & 36.5 & 0.208 & 46.3 & 0.263 & 54.8 & 0.327 \\
\hline I & IV & 34.1 & 0.186 & 39.4 & 0.229 & 45.6 & 0.284 \\
\hline I & V & 34.2 & 0.185 & 39.8 & 0.227 & 46.0 & 0.283 \\
\hline
\end{tabular}

NBO analyses (Table 9) for the $\mathrm{Cl}, \mathrm{Br}$, and I derivatives reveal important orbital stabilization energies due to the interaction between the lone pairs of the chalcogen atom and the antibonding $\mathrm{O}-\mathrm{Y}$ orbital $(\mathrm{Y}=\mathrm{Cl}, \mathrm{Br}$, and $\mathrm{I})$. Similar stabilization energies have been reported for other complexes with hypohalous acids. ${ }^{20,24}$ In the same way, weak interactions with a relatively small charge transfer are found for the $\mathrm{FOH}$ complexes. In addition, the orbital stabilization energy by the electron donation from the lone pair of the chalcogen to the $\mathrm{O}-\mathrm{F}$ antibonding orbital is almost negligible.

\section{General discussion}

Relationship between MEP and interaction energies. Relationships between the electrostatic potential and the interaction energy in hydrogen and halogen bonds have been reported in the literature. ${ }^{12,59-61}$ Fig. 4 shows the correlation between

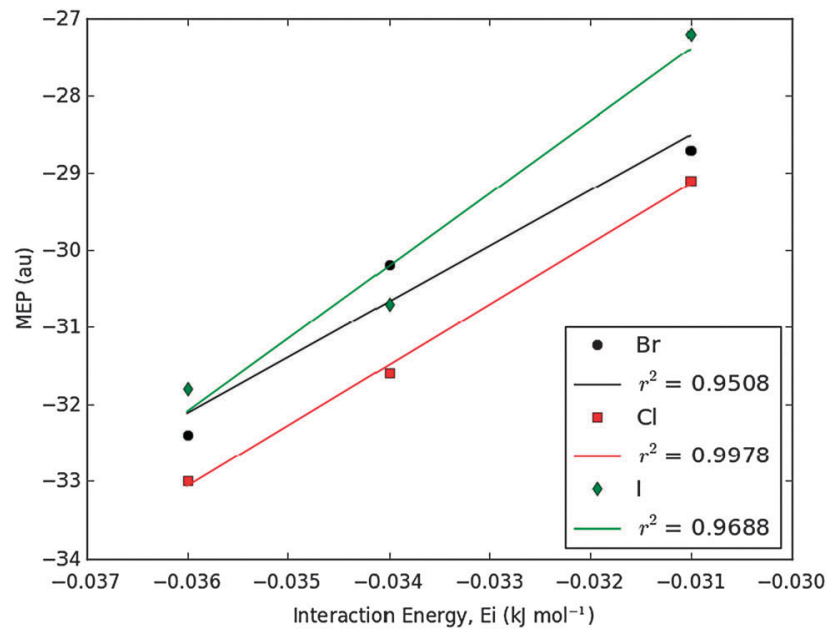

the molecular electrostatic potential values of the chalcogen lone pairs on the $\mathrm{vdW}$ isosurface and the interaction energy of the complex with $\mathrm{YOH}(\mathrm{Y}=\mathrm{Cl}, \mathrm{Br}$, and $\mathrm{I})$ in configurations I and II which exhibit a hydrogen bond. Good linear correlations have been found in both configurations which indicate the importance of the electrostatic interaction in these complexes. Even though in both configurations, I and II, similar $\mathrm{HB}$ interactions are established the fact that in configuration II additional weak interactions are formed limits the possibility to mix the results in unique correlations.

Fig. 5 illustrates the MEP positive values of the $\sigma$-hole of $\mathrm{YOH}(\mathrm{Y}=\mathrm{Cl}, \mathrm{Br}$, and $\mathrm{I}) v s$. the interaction energies in the complexes IV, for each $\mathrm{X}\left(\mathrm{CH}_{3}\right)_{2}$ subset $(\mathrm{X}=\mathrm{S}$, Se, and $\mathrm{Te})$. Again, the linear correlations present very good $R^{2}$ values $(0.99,0.99$, and 0.98 for $\mathrm{S}, \mathrm{Se}$, and $\mathrm{Te}$, respectively), even better than in the hydrogen bond complexes. These results confirm the importance of the electrostatic interaction already indicated in previous articles. ${ }^{12,26,59-61}$ In the case of fluorine derivatives, acceptable relationships have not been found, either in configuration II or in configuration IV.

AIM analysis. A total of 42 interactions have been found, 21 hydrogen bonds, 15 halogen bonds and $6 \mathrm{CH}$. . O contacts. In the case of the $\mathrm{HBs}$, the $\mathrm{X} \cdot \mathrm{H}$ distances vary from 2.17 to $2.32 \AA$. The nature of the HBs has been characterized based on the value at the bond critical point of the Laplacian, $C$ ratio $(C=|V| / G$, where $V$ and $G$ are the electron potential and kinetic energy densities, respectively) ${ }^{62}$ and $H$, the total electron

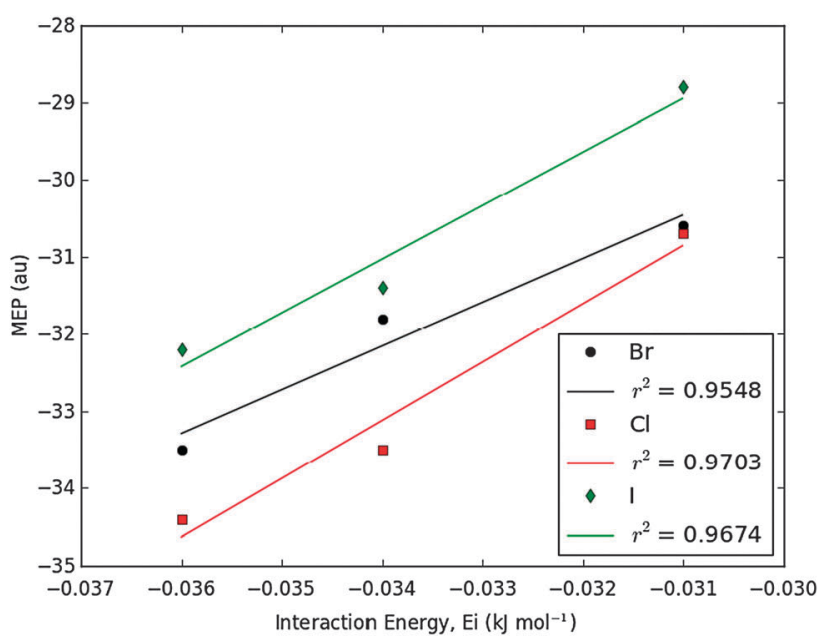

Fig. 4 Molecular electrostatic potential, MEP (a.u.) of the $\mathrm{X}$ lone pairs $\left(\mathrm{X}=\mathrm{S}\right.$, Se, and Te) vs. interaction energy, $E_{\mathrm{i}}\left(\mathrm{kJ} \mathrm{mol}^{-1}\right)$ for configurations I (left) and II (right) with $\mathrm{YOH}(\mathrm{Y}=\mathrm{Cl}, \mathrm{Br}$, and I). 


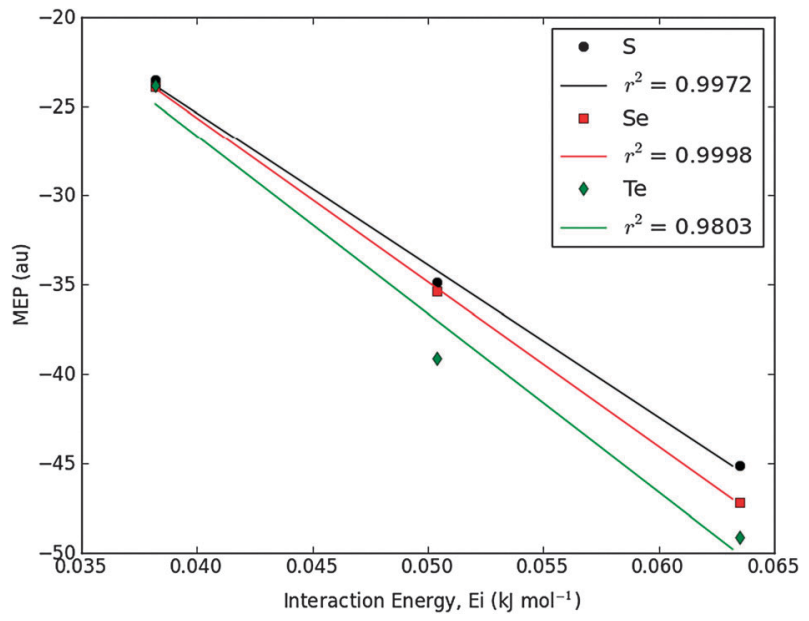

Fig. 5 Molecular electrostatic potential, MEP (a.u.) of the $\sigma$-hole of $\mathrm{YOH}\left(\mathrm{Y}=\mathrm{Cl}, \mathrm{Br}\right.$, and I) vs. interaction energy, $E_{\mathrm{i}}\left(\mathrm{kJ} \mathrm{mol}^{-1}\right)$ for $\mathrm{X}\left(\mathrm{CH}_{3}\right)_{2}$ configuration IV.

density energy $(H=V+G) .{ }^{63}$ Based on the positive values of the Laplacian, $C$ values between 1 and 2 and negative values of $H$, the $\mathrm{HB}$ interactions found here can be classified as pure closed shell interactions with a partial covalent character.

In addition, if the $\mathrm{HB}$ are classified based on the nature of the $\mathrm{HB}$ acceptor ( $\mathrm{S}, \mathrm{Se}$, or $\mathrm{Te}$ ), exponential relationships between the electron density at the BCP and the corresponding interatomic distance are obtained (Fig. 6). Similar relationships have been described for other weak interactions ${ }^{64,65}$ and for different HBs. ${ }^{66,67}$

In the case of the $\mathrm{C}-\mathrm{H} \cdots \mathrm{O}$ contacts, the $\mathrm{H} \cdots \mathrm{O}$ distances range from 2.44 to $2.60 \AA$. The AIM analysis of the $\mathrm{CH} \cdots \mathrm{O}$ interactions reveals two BCPs between the $\mathrm{H}$ atoms of both methylenes and the $\mathrm{O}$ atom, with electron densities $(\rho)$ which vary from 0.006 to 0.009 a.u. (see ESI $\dagger$ ). No relationship between distance and electron density has been found for the $\mathrm{C}-\mathrm{H}$. . O interaction due to the lack of enough data to perform a fitting.

The $\mathrm{X} \cdots \mathrm{Y}$ interactions in configurations $\mathbf{I V}$ and $\mathbf{V}$ present distances which vary from 2.68 to $3.23 \AA$ characterized by the existence of BCP between the chalcogen and halogen atom with $\rho$ between 0.008 and 0.047 a.u. Fig. 7 illustrates the correlation between the $\mathrm{X} \cdot \mathrm{YY}$ distance and the Laplacian. The series have been classified according to the electron donor (S, Se, and Te), and afterwards exponential relationships vs. interacting distances have been found with $R^{2}=0.96,0.95$ and 0.94 , respectively.

Harmonic frequencies. The stretching frequencies have been gathered in Table 10, O-H stretching for the configurations I and II, C-H stretching for complexes in configuration III, and $\mathrm{O}-\mathrm{Y}$ for the conformations $\mathbf{I V}$ and $\mathbf{V}$. The formation of a hydrogen bond has been associated with a red shift of the $\nu_{\mathrm{O}-\mathrm{H}}$ stretching frequency and has been reported as a characteristic for these interactions in the literature. ${ }^{68}$ Previous studies on interactions with hypohalous acids ${ }^{24}$ and also on different complexes $^{69}$ resulted in an increasing number of cases where there is a blue shift in the $\mathrm{O}-\mathrm{H}$ stretching frequencies. A red shift in the $\mathrm{O}-\mathrm{H}$ stretching frequencies is always observed for

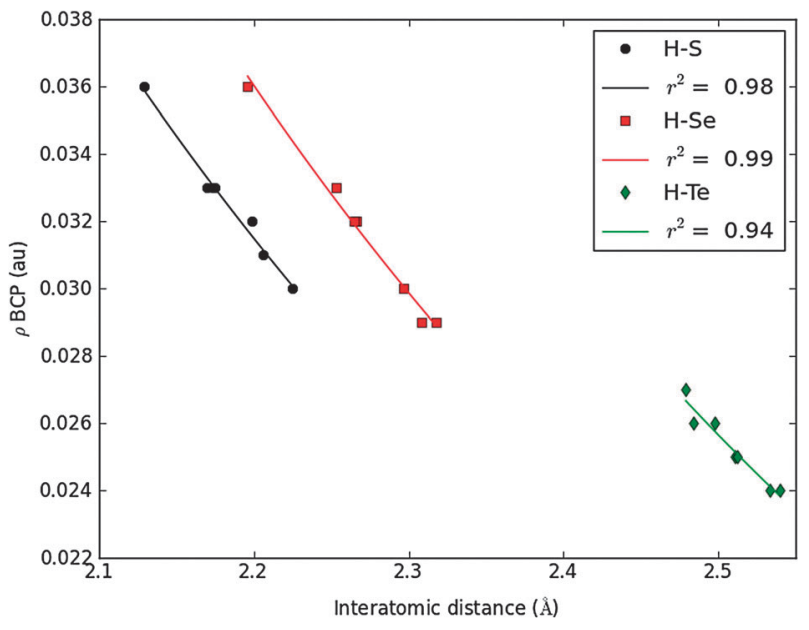

Fig. 6 Relationship between the interatomic distance $(\AA)$ and the value of the electron density at BCP (a.u.) for HB interactions. The fitted relationships present $R^{2}=0.98,0.99$, and 0.94 for $\mathrm{S} \cdots \mathrm{H}$, $\mathrm{Se} \cdots \mathrm{H}$, and $\mathrm{Te} \cdots \mathrm{H}$ data, respectively.

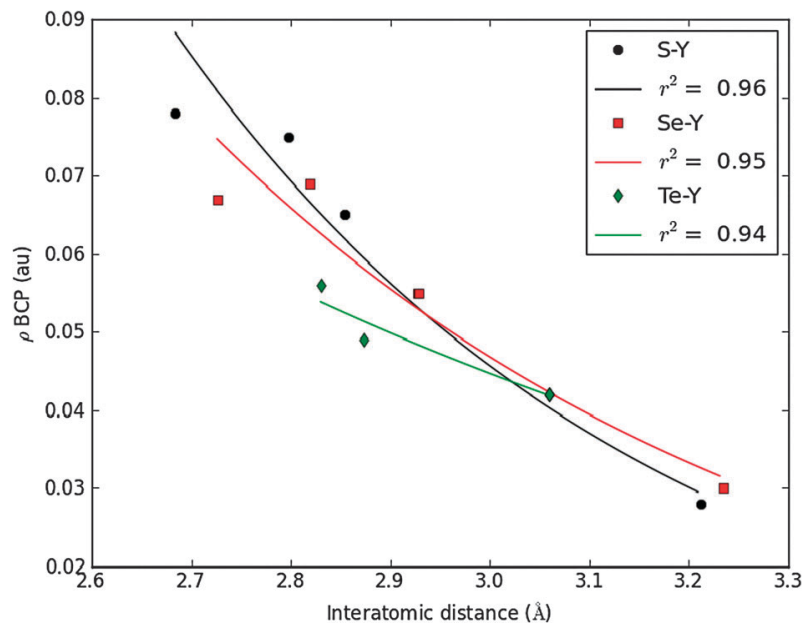

Fig. 7 Relationship between the interatomic distance $(\AA)$ and the value of the Laplacian $\left(\nabla^{2}\right)$ at BCP (a.u.) for X $\cdots$ Y interactions. The fitted relationships present $R^{2}=0.96,0.95$, and 0.94 for $\mathrm{S} \cdots \mathrm{Y}$, $\mathrm{Se} \cdots \mathrm{Y}$, and $\mathrm{Te} \cdots \mathrm{Y}$ data, respectively.

the complexes I and II with values of the variation of the harmonic frequencies between -319 and $-486 \mathrm{~cm}^{-1}$.

The complexes III show blue shifts in the $\mathrm{C}-\mathrm{H}$ stretching of both symmetric and asymmetric modes (only the asymmetric ones are listed in Table 10). The $\mathrm{S}\left(\mathrm{CH}_{3}\right)_{2}: \mathrm{ClOH}$ complex is an exception because a blue shift is not observed but a red one. However, the larger the size of the halogen, the larger is the blue shift observed.

The complexes in configurations $\mathbf{I V}$ and $\mathbf{V}$ show red shifts for the $\mathrm{O}-\mathrm{Y}$ stretching. The $\mathrm{FOH}$ complexes show variations of the stretching band between -16 and $-22 \mathrm{~cm}^{-1}$. In the rest of the complexes of the configurations IV and $\mathbf{V}$, the variations are between 98 and $275 \mathrm{~cm}^{-1}$. In the same complexes, the $\mathrm{H}-\mathrm{O}$ stretching frequencies present red shifts from 1 to $70 \mathrm{~cm}^{-1}$, except in $\mathrm{S}\left(\mathrm{CH}_{3}\right)_{2}: \mathrm{ClOH}, \mathrm{Te}\left(\mathrm{CH}_{3}\right)_{2}: \mathrm{FOH}$ and $\mathrm{Te}\left(\mathrm{CH}_{3}\right)_{2}: \mathrm{ClOH}$ (both conf. IV) which exhibit a small blue shift (2, 13 and $3 \mathrm{~cm}^{-1}$, respectively), except in the iodine complexes where a variation between -58 and $-70 \mathrm{~cm}^{-1}$ has been found. 
Table 10 Bond stretching frequencies of the monomers and variation upon complexation $\left(\mathrm{cm}^{-1}\right)$ calculated at the MP2/aug'-cc-pVTZ/augcc-pVTZ-PP computational level

\begin{tabular}{|c|c|c|c|c|}
\hline \multicolumn{2}{|l|}{$\mathrm{YOH}$} & \multirow{2}{*}{$\begin{array}{l}\text { O-H stretching } \\
3764\end{array}$} & \multicolumn{2}{|l|}{$\mathrm{O}-\mathrm{Y}$ stretching } \\
\hline $\mathrm{F}$ & & & 979 & \\
\hline $\mathrm{Cl}$ & & 3771 & 765 & \\
\hline $\mathrm{Br}$ & & 3793 & 673 & \\
\hline \multirow[t]{3}{*}{ I } & & 3846 & 632 & \\
\hline & Conf. & $\mathrm{S}$ & $\mathrm{Se}$ & $\mathrm{Te}$ \\
\hline & & $\mathrm{O}-\mathrm{H}$ stretching & $\mathrm{O}-\mathrm{H}$ stretching & $\mathrm{O}-\mathrm{H}$ stretching \\
\hline $\mathrm{F}$ & I & & & \\
\hline $\mathrm{Cl}$ & I & -410 & -418 & -391 \\
\hline $\mathrm{Br}$ & I & -445 & -474 & -402 \\
\hline I & I & -475 & -486 & -451 \\
\hline $\mathrm{F}$ & II & -368 & -372 & -328 \\
\hline $\mathrm{Cl}$ & II & -389 & -399 & -361 \\
\hline $\mathrm{Br}$ & II & -408 & -430 & -379 \\
\hline \multirow[t]{2}{*}{ I } & II & -430 & -443 & -417 \\
\hline & & $\mathrm{C}-\mathrm{H}$ stretching & $\mathrm{C}-\mathrm{H}$ stretching & $\mathrm{C}-\mathrm{H}$ stretching \\
\hline $\mathrm{F}$ & III & & & \\
\hline $\mathrm{Cl}$ & III & -1 & 4 & 11 \\
\hline $\mathrm{Br}$ & III & 1 & 10 & 11 \\
\hline \multirow[t]{2}{*}{ I } & III & & & \\
\hline & & $\mathrm{O}-\mathrm{Y}$ stretching & $\mathrm{O}-\mathrm{Y}$ stretching & $\mathrm{O}-\mathrm{Y}$ stretching \\
\hline $\mathrm{F}$ & IV & -16 & -22 & -21 \\
\hline $\mathrm{Cl}$ & IV & -111 & -158 & -275 \\
\hline $\mathrm{Br}$ & IV & -122 & -154 & -204 \\
\hline I & IV & -98 & -112 & -137 \\
\hline I & $\mathbf{V}$ & -98 & -112 & -137 \\
\hline
\end{tabular}

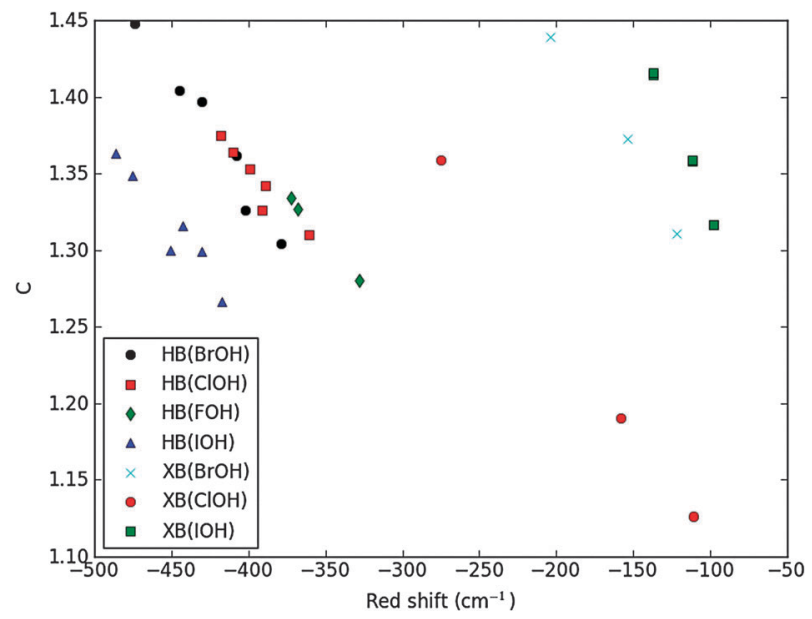

Fig. 8 Electron density $C$ ratio versus $\mathrm{OH}$ frequencies $\left(\mathrm{cm}^{-1}\right)$ in $\mathrm{YOH}$ complexes for the configurations I, II, and IV.

Fig. 8 illustrates the comparison of the red shift in the hydrogen and halogen bonded complexes and the electron density $C$ ratio, which indicates the degree of covalency of the HB. It shows linear relations between these two parameters when the complexes are divided based on the nature of the electron acceptor moiety.

SAPT-DFT. The different terms of the interaction energy have been obtained by means of SAPT-DFT calculations. All these data have been included in the ESI. $\dagger$ The percentages of each attractive force with respect to the total attractive forces have been summarized in Table 11.

It is observed that the electrostatic term governs the attractive forces in the complexes formed by $\mathrm{HB}$ interactions (configurations I and II), its contribution being more than $50 \%$
Table 11 Percentage of each attractive component to the total attractive energy obtained at the SAPT-DFT/aug'-cc-pVTZ/aug-ccpVTZ-PP computational level

\begin{tabular}{|c|c|c|c|c|c|c|c|c|c|c|}
\hline & \multirow[b]{2}{*}{ Conf. } & \multicolumn{3}{|l|}{$\mathrm{S}$} & \multicolumn{3}{|l|}{$\mathrm{Te}$} & \multicolumn{3}{|l|}{$\mathrm{Te}$} \\
\hline & & $\% E_{\mathrm{el}}$ & $\% E_{\mathrm{i}}$ & $\% E_{\mathrm{d}}$ & $\% E_{\mathrm{el}}$ & $\% E_{\mathrm{i}}$ & $\% E_{\mathrm{d}}$ & $\% E_{\mathrm{el}}$ & $\% E_{\mathrm{i}}$ & $\% E_{\mathrm{d}}$ \\
\hline $\mathrm{F}$ & I & & & & & & & & & \\
\hline $\mathrm{Cl}$ & I & 55 & 16 & 29 & 54 & 16 & 29 & 53 & 17 & 30 \\
\hline $\mathrm{Br}$ & I & 54 & 16 & 30 & 53 & 17 & 31 & 52 & 17 & 31 \\
\hline I & I & 53 & 17 & 31 & 51 & 18 & 31 & 48 & 22 & 30 \\
\hline $\mathrm{F}$ & II & 58 & 16 & 26 & 57 & 16 & 27 & 55 & 17 & 28 \\
\hline $\mathrm{Cl}$ & II & 56 & 15 & 29 & 55 & 15 & 29 & 54 & 16 & 31 \\
\hline $\mathrm{Br}$ & II & 55 & 15 & 30 & 55 & 15 & 30 & 53 & 15 & 32 \\
\hline I & II & 54 & 16 & 30 & 52 & 17 & 31 & 49 & 20 & 31 \\
\hline $\mathrm{Cl}$ & III & 38 & 2 & 60 & 38 & 2 & 60 & 37 & 2 & 60 \\
\hline $\mathrm{Br}$ & III & 40 & 2 & 58 & 40 & 3 & 57 & 39 & 3 & 59 \\
\hline $\mathrm{F}$ & IV & 39 & 2 & 59 & 42 & 1 & 57 & 44 & 0 & 55 \\
\hline $\mathrm{Cl}$ & IV & 60 & 11 & 29 & 60 & 14 & 27 & 56 & 23 & 21 \\
\hline $\mathrm{Br}$ & IV & 57 & 23 & 20 & 55 & 28 & 18 & 50 & 34 & 16 \\
\hline I & IV & 37 & 51 & 12 & 34 & 54 & 11 & 31 & 60 & 10 \\
\hline I & V & 37 & 51 & 12 & 34 & 54 & 11 & 30 & 60 & 10 \\
\hline
\end{tabular}

in almost all the cases. The induction and dispersion terms account for 17 and $30 \%$ of the total attractive forces in the same complexes. This energy partition remains nearly constant along the chalcogen and the halogen series.

The complexes in configuration III are dominated by the dispersion terms which represent between 57 and $60 \%$ of the total attractive energy. The induction in those complexes seems to be almost negligible.

The complexes in configurations IV and $\mathbf{V}$ show different partition schemes depending on the interacting halogen atom. In the case of fluorine derivatives the dispersion energy is the most important term closely followed by the electrostatic one. The electrostatic term is the one which shows the highest contribution for the $\mathrm{HOCl}$ complexes decreasing with the size of the halogen. An opposite trend is observed in the induction term that becomes the most important attractive contribution for the iodine derivatives, reflecting the importance of the polarization as the size of the halogen atom increases. The dispersion energy decreases with the size of the halogen as well. A similar pattern is observed along the chalcogen series.

\section{Conclusions}

- The interaction between hypohalous acids, $\mathrm{YOH}(\mathrm{Y}=\mathrm{F}$, $\mathrm{Cl}, \mathrm{Br}$, and $\mathrm{I})$, and dimethylchalcogen derivatives, $\mathrm{X}\left(\mathrm{CH}_{3}\right)_{2}$ $(\mathrm{X}=\mathrm{S}, \mathrm{Se}$, and Te), have been studied by MP2 methodology. Electrostatic and electron density properties of the isolated monomers have been characterized in order to analyze the potential interacting areas. The binary complexes found have been assorted in five configurations, according to their binding nature and configuration.

- The interaction energies and structural parameters have been obtained and discussed, finding that the complexes with the highest interaction energy correspond to those with $\mathrm{IOH}$ and $\mathrm{BrOH}$ in configurations IV and $\mathbf{V}$. The most stable complexes of $\mathrm{FOH}$ and $\mathrm{ClOH}$ are associated with $\mathrm{HB}$ interactions.

- The NBO results have determined that interactions resulted from the donation of the chalcogen lone pairs to the antibonding orbital of $\mathrm{OH}$ in the $\mathrm{HB}$ interactions or $\mathrm{OY}$ in the halogen bond contacts (XB). 
- Regarding the harmonic vibrational frequencies, red shifts have been found in the $\mathrm{OH}$ and $\mathrm{OY}$ stretching modes, in the $\mathrm{HB}$ complexes (configurations I and II), and in the XB complexes (configurations IV and V), respectively. Small blue shifts have been found in the $\mathrm{C}-\mathrm{H}$ stretching modes of the complexes in configuration III.

- DFT-SAPT calculations have permitted the analysis of the different terms of the interaction energy. An electrostatic attractive term is dominant in the complexes with $\mathrm{HB}$ (configurations I and II) and with XB (configurations IV and V) except in a few cases of $\mathrm{XB}$ in which the dispersion (FOH) and induction $(\mathrm{IOH})$ terms account for the greatest contribution to the total attractive forces. In the case of configuration III, the dispersion term governs the interaction energy.

\section{Acknowledgements}

We thank the Ministerio de Ciencia e Innovación (Project No. CTQ2009-13129-C02-02), the Spanish MEC (CTQ200762113), the Comunidad Autónoma de Madrid (Project MADRISOLAR2, Ref. S2009/PPQ-1533) for continuous support. Thanks are given to the CTI (CSIC) and the Centro de Computación Científica of the Universidad Autónoma de Madrid for allocation of computer time.

\section{References}

1 D. Simpson, W. Winiwarter, G. Börjesson, S. Cinderby, A. Ferreiro, A. Guenther, C. N. Hewitt, R. Janson, M. A. K. Khalil, S. Owen, T. E. Pierce, H. Puxbaum, M. Shearer, U. Skiba, R. Steinbrecher, L. Tarrasón and M. G. Öquist, J. Geophys. Res., 1999, 104, 8113-8152.

2 R. J. Ferek, P. V. Hobbs, L. F. Radke, J. A. Herring, W. T. Sturges and G. F. Cota, J. Geophys. Res., [Atmos.], 1995, 100, 26093-26104.

3 R. Y.-W. Chang, S. J. Sjostedt, J. R. Pierce, T. N. Papakyriakou, M. G. Scarratt, S. Michaud, M. Levasseur, W. R. Leaitch and J. P. D. Abbatt, J. Geophys. Res., [Atmos.], 2011, 116, D00S03.

4 G. P. Yang, H. H. Zhang, L. M. Zhou and J. Yang, Cont. Shelf Res., 2011, 31, 1325-1335.

5 M. Luce, M. Levasseur, M. G. Scarratt, S. Michaud, S. J. Royer, R. Kiene, C. Lovejoy, M. Gosselin, M. Poulin, Y. Gratton and M. Lizotte, J. Geophys. Res., [Oceans], 2011, 116, C00G06.

6 T. G. Chasteen and R. Bentley, ed. F. A. Devillanova, The Royal Society of Chemistry, Cambridge, 2007, ch. 11.

7 R. S. T. Basnayake, J. H. Bius, O. M. Akpolat and T. G. Chasteen, Appl. Organomet. Chem., 2001, 15, 499-510.

8 H. B. Singh and N. Sudha, Polyhedron, 1996, 15, 745-763.

9 I. Hargittai and B. Rozsondai, in The chemistry of organic selenium and tellurium compounds, John Wiley \& Sons, Chichester, 1986, vol. 1 , ch. 3 .

10 V. K. Yadav, A. Yadav and R. A. Poirier, THEOCHEM, 1989, 186, 101-116.

11 R. A. Poirier and I. G. Csizmadia, The chemistry of organic selenium and tellurium compounds, John Wiley \& Sons, Chichester, 1986, vol. 1, ch. 2.

12 P. Politzer, J. S. Murray and T. Clark, Phys. Chem. Chem. Phys., 2010, 12, 7748-7757.

13 A. C. Legon, Phys. Chem. Chem. Phys., 2010, 12, 7736-7747.

14 E. H. Appelman, Acc. Chem. Res., 1973, 6, 113-117.

15 M. Solimannejad, I. Alkorta and J. Elguero, Chem. Phys. Lett., 2008, 454, 201-206.

16 M. Solimannejad and L. O. Pejov, J. Phys. Chem. A, 2005, 109, $825-831$.

17 A. F. Jalbout, X. H. Li and M. Solimannejad, Chem. Phys. Lett., 2006, 420, 204-208.

18 M. Solimannejad, I. Alkorta and J. Elguero, Chem. Phys. Lett., 2007, 449, 23-27.
19 M. Solimannejad and S. Scheiner, J. Phys. Chem. A, 2008, 112, 4120-4124.

20 I. Alkorta, F. Blanco, M. Solimannejad and J. Eiguero, J. Phys. Chem. A, 2008, 112, 10856-10863.

21 B. Jing, Q. Z. Li, R. Li, B. A. Gong, Z. B. Liu, W. Z. Li, J. B. Cheng and J. Z. Sun, Comput. Theor. Chem., 2011, 963, 417-421.

22 Q. Z. Li, B. Jing, R. Li, Z. B. Liu, W. Z. Li, F. Luan, J. B. Cheng, B. A. Gong and J. Z. Sun, Phys. Chem. Chem. Phys., 2011, 13, 2266-2271.

23 Q. Z. Li, X. S. Xu, T. Liu, B. Jing, W. Z. Li, J. B. Cheng, B. A. Gong and J. Z. Sun, Phys. Chem. Chem. Phys., 2010, 12, $6837-6843$.

24 F. Blanco, I. Alkorta, M. Solimannejad and J. Elguero, J. Phys. Chem. A, 2009, 113, 3237-3244.

25 Q. Z. Li, R. Li, P. Guo, H. Li, W. Z. Li and J. B. Cheng, Comput. Theor. Chem., 2012, 980, 56-61.

26 P. Politzer, J. S. Murray and P. Lane, Int. J. Quantum Chem., 2007, 107, 3046-3052.

27 J. Murray, M. Concha, P. Lane, P. Hobza and P. Politzer, J. Mol. Model., 2008, 14, 699-704.

28 P. Politzer and J. S. Murray, ed. J. Leszczynski and M. K. Shukla, Springer Netherlands, 2010, pp. 149-163.

29 J. E. Del Bene, J. Phys. Chem., 1993, 97, 107-110.

30 T. H. Dunning, J. Chem. Phys., 1989, 90, 1007-1023.

31 D. E. Woon and T. H. Dunning, J. Chem. Phys., 1995, 103, $4572-4585$.

32 K. A. Peterson, D. Figgen, E. Goll, H. Stoll and M. Dolg, J. Chem. Phys., 2003, 119, 11113-11123.

33 K. A. Peterson, B. C. Shepler, D. Figgen and H. Stoll, J. Phys. Chem. A, 2006, 110, 13877-13883.

34 S. F. Boys and F. Bernardi, Mol. Phys., 1970, 19, 553-566.

35 I. Alkorta, C. Trujillo, J. Elguero and M. Solimannejad, Comput. Theor. Chem., 2011, 967, 147-151.

36 M. J. Frisch, G. W. Trucks, H. B. Schlegel, G. E. Scuseria, M. A. Robb, J. R. Cheeseman, G. Scalmani, V. Barone, B. Mennucci, G. A. Petersson, H. Nakatsuji, M. Caricato, X. Li, H. P. Hratchian, A. F. Izmaylov, J. Bloino, G. Zheng, J. L. Sonnenberg, M. Hada, M. Ehara, K. Toyota, R. Fukuda, J. Hasegawa, M. Ishida, T. Nakajima, Y. Honda, O. Kitao, H. Nakai, T. Vreven, J. Montgomery, J. A. J. E. Peralta, F. Ogliaro, M. Bearpark, J. J. Heyd, E. Brothers, K. N. Kudin, V. N. Staroverov, R. Kobayashi, J. Normand, K. Raghavachari, A. Rendell, J. C. Burant, S. S. Iyengar, J. Tomasi, M. Cossi, N. Rega, N. J. Millam, M. Klene, J. E. Knox, J. B. Cross, V. Bakken, C. Adamo, J. Jaramillo, R. Gomperts, R. E. Stratmann, O. Yazyev, A. J. Austin, R. Cammi, C. Pomelli, J. W. Ochterski, R. L. Martin, K. Morokuma, V. G. Zakrzewski, G. A. Voth, P. Salvador, J. J. Dannenberg, S. Dapprich, A. D. Daniels, Ö. Farkas, J. B. Foresman, J. V. Ortiz, J. Cioslowski and D. J. Fox, Gaussian, Inc., Wallingford CT, 2009.

37 R. F. W. Bader, M. T. Carroll, J. R. Cheeseman and C. Chang, J. Am. Chem. Soc., 1987, 109, 7968-7979.

38 F. Bulat, A. Toro-Labbé, T. Brinck, J. Murray and P. Politzer, J. Mol. Model., 2010, 16, 1679-1691.

39 R. F. W. Bader, Atoms in Molecules: A Quantum Theory, Clarendon Press, Oxford, 1990.

40 P. L. A. Popelier, Atoms In Molecules. An introduction, Prentice Hall, Harlow, England, 2000.

41 T. A. Keith, 11.10.16 edn., 2011, TK Gristmill Software, (aim. tkgristmill.com).

42 A. E. Reed, L. A. Curtiss and F. Weinhold, Chem. Rev., 1988, 88, 899-926.

43 G. Chałasiński and M. M. Szcześniak, Chem. Rev., 2000, 100, 4227-4252.

44 J. P. Perdew, K. Burke and M. Ernzerhof, Phys. Rev. Lett., 1996, 77, 3865-3868.

45 J. D. Scott, G. C. Causley and B. R. Russell, J. Chem. Phys., 1973, 59, 6577-6586.

46 J. Berkowit, J. L. Dehmer and E. H. Appelman, Chem. Phys. Lett., 1973, 19, 334-336.

47 D. Colbourne, D. C. Frost, C. A. McDowell and N. P. C. Westwood, J. Chem. Phys., 1978, 68, 3574-3580.

48 B. Ruscic and J. Berkowitz, J. Chem. Phys., 1994, 101, 7795-7803.

49 P. S. Monks, L. J. Stief, D. C. Tardy, J. F. Liebman, Z. Y. Zhang, S. C. Kuo and R. B. Klemm, J. Phys. Chem., 1995, 99, 16566-16570. 
50 H.-J. Werner, P. J. Knowles, F. R. Manby, M. Schütz, P. Celani, G. Knizia, T. Korona, R. Lindh, A. Mitrushenkov, G. Rauhut, T. B. Adler, R. D. Amos, A. Bernhardsson, A. Berning, D. L. Cooper, M. J. O. Deegan, A. J. Dobbyn, F. Eckert, E. Goll, C. Hampel, A. Hesselmann, G. Hetzer, T. Hrenar, G. Jansen, C. Köppl, Y. Liu, A. W. Lloyd, R. A. Mata, A. J. May, S. J. McNicholas, W. Meyer, M. E. Mura, A. Nicklass, P. Palmieri, K. Pflüger, R. Pitzer, M. Reiher, T. Shiozaki, H. Stoll, A. J. Stone, R. Tarroni, T. Thorsteinsson, M. Wang and A. Wolf, Molpro, Cardiff, UK, 1 edn, 2010.

51 L. Pierce and M. Hayashi, J. Chem. Phys., 1961, 35, 479-485.

52 H. Kim, E. F. Pearson and E. H. Appelman, J. Chem. Phys., 1972, 56, $1-3$.

53 C. M. Deeley, J. Mol. Spectrosc., 1987, 122, 481-489.

54 E. A. Cohen, G. A. McRae, T. L. Tan, R. R. Friedl, J. W. C. Johns and M. Noel, J. Mol. Spectrosc., 1995, 173, 55-61.

55 H. Ozeki and S. Saito, J. Chem. Phys., 2004, 120, 5110-5116.

56 T. Clark, M. Hennemann, J. Murray and P. Politzer, J. Mol. Model., 2007, 13, 291-296.

57 F. Weinhold and C. R. Landis, Valency and Bonding. A Natural Bond Orbital Donor-Acceptor Perspective, Cambridge Press, Cambridge, 2005.
58 I. Alkorta, I. Rozas and J. Elguero, J. Phys. Chem. A, 1998, 102, 9278-9285.

59 J.-W. Zou, Y.-J. Jiang, M. Guo, G.-X. Hu, B. Zhang, H.-C. Liu and Q.-S. Yu, Chem.-Eur. J., 2005, 11, 740-751.

60 A. Bauza, D. Quinonero, A. Frontera and P. M. Deya, Phys. Chem. Chem. Phys., 2011, 13, 20371-20379.

61 K. Riley, J. Murray, J. Fanfrlík, J. Řezáč, R. Solá, M. Concha, F. Ramos and P. Politzer, J. Mol. Model., 2011, 17, 3309-3318.

62 E. Espinosa, I. Alkorta, J. Elguero and E. Molins, J. Chem. Phys., 2002, 117, 5529-5542.

63 I. Rozas, I. Alkorta and J. Elguero, J. Am. Chem. Soc., 2000, 122, 11154-11161.

64 G. Sanchez-Sanz, I. Alkorta and J. Elguero, Mol. Phys., 2011, 109, $2543-2552$.

65 G. Sanchez-Sanz, C. Trujillo, I. Alkorta and J. Elguero, ChemPhysChem, 2012, 13, 496-503.

66 O. Picazo, I. Alkorta and J. Elguero, J. Org. Chem., 2003, 68, $7485-7489$.

67 I. Mata, I. Alkorta, E. Molins and E. Espinosa, Chem.-Eur. J., 2010, 16, 2442-2452.

68 G. C. Pimentel and A. L. McClellan, The Hydrogen Bond, Freeman, San Francisco, CA, 1960.

69 P. Hobza and Z. Havlas, Chem. Rev., 2000, 100, 4253-4264. 